\title{
Hydraulic Scaling and Similitude from Model to Prototype
}

\author{
Ajim A. Mokashi, Piyusha S. Hirpurkar
}

\begin{abstract}
In this paper, the corresponding diameter of sediment in prototype is determine by using Shield's parameter. This simulation has been undertaken to similitude the relationship between prototype and its model. A model and prototype are designed to be similitude geometrically, dynamically and kinematically. The studies regarding sediment transport similitude for hydraulic modeling, a very few researcher gives the predictive methodologies. Firstly Shield was started to consider sediment particle motion after taking into account, the forces act on the sediment particles and then afterward apply the principles of similitude similarity. The sediment used in undistorted model(tiling flume) is sieved river sand. The mechanical sieve shaker, analysis was used to determine the mean particle size $(250=0.828 \mathrm{~mm})$ and the corresponding diameter of sediment in prototype is determine by using Shield's parameter which predict sediment size $(d 50=41.43 \mathrm{~mm})$.
\end{abstract}

Keywords : Sediment, Similitude, Model, Prototype, Shield's parameter, Hydraulic modeling.

\section{INTRODUCTION}

The scaling of sediment in such a manner that similarity between model and prototype implies that Shield's parameter and the particle grain size Reynolds number should be same in the model and prototype. Practically the scaling is not only related about its physical dimensions, but it is also similitude the fluid properties such as fluid density, viscosity, etc. This study is to be carried out for correlating similitude used for undistorted model (tiling flume) with prototype. The study related to hydraulic structures by using scaling model is cost effective for performance investigation of any existing hydraulic structure, proposed hydraulic structure and for any modification in hydraulic structure. For general guideline for the selection of model sediments the mean particle size should be more than $0.7 \mathrm{~mm}$, to avoid forming ripples Raudkivi and Ettema(1983).The grain size standard deviation is calculated $\sigma g=1.24$. The bed materials used for this study is considered to be uniform in size, the grain size standard deviation of sediment particle should be less than 1.30 for uniform size sediments according to Raudkivi(1998). Various calculations are made in this study regards, calculation of bed shear stress for undistorted model(tiling flume) using Shield's parameter and scaling

Revised Manuscript Received on September 25, 2019

Ajim A. Mokashi, M-Tech Student (Environment and Water Resources), Department of Civil Engineering, College of Engineering, Pune, India. Email: ajimmokashi2018@gmail.com

Prof. Piyusha S. Hirpurkar, Assistant Professor, Department of Civil Engineering, College of Engineering, Pune, India. model.

\subsection{Shield's diagram and incipient motion study}

This diagram is theoretical approach for calculation of critical motion and this graph is plotted between boundary Reynolds number and Shields critical stress. This diagram explain critical shear stress $(\tau c)$. The dimensionless parameter should be correlate in between prototype and its model for properly simulate of sediment and other parameters. Shear force is the main cause behind movement of particles inside the fluid. The curve is generated for incipient motion condition when graph is plotted between Reynolds no( $\left.\mathrm{R}^{*}\right)$ with dimensionless shear $\operatorname{stress}\left(\tau^{*}\right)$ and this $\left(\tau^{*}\right)$ value that lie on this curve are called as critical Shield's parameter. The determination of incipient motion has importance in the theory of sediment transport. The particles of sediment are move with the fluid is hydraulic incipient motion condition of that sediment particles. With the help of Shield's diagram and approach of critical tractive force, the threshold of bed material is calculated. The condition of incipient is occurs when initiation in sediment occurs, for better understanding about Shields diagram and other shields parameter refer figure1.

The parameters necessary to establish similitude of sediment are particle Reynolds number and Shield's parameter.

1. for grain Reynolds number

2. Shields Parameter. 


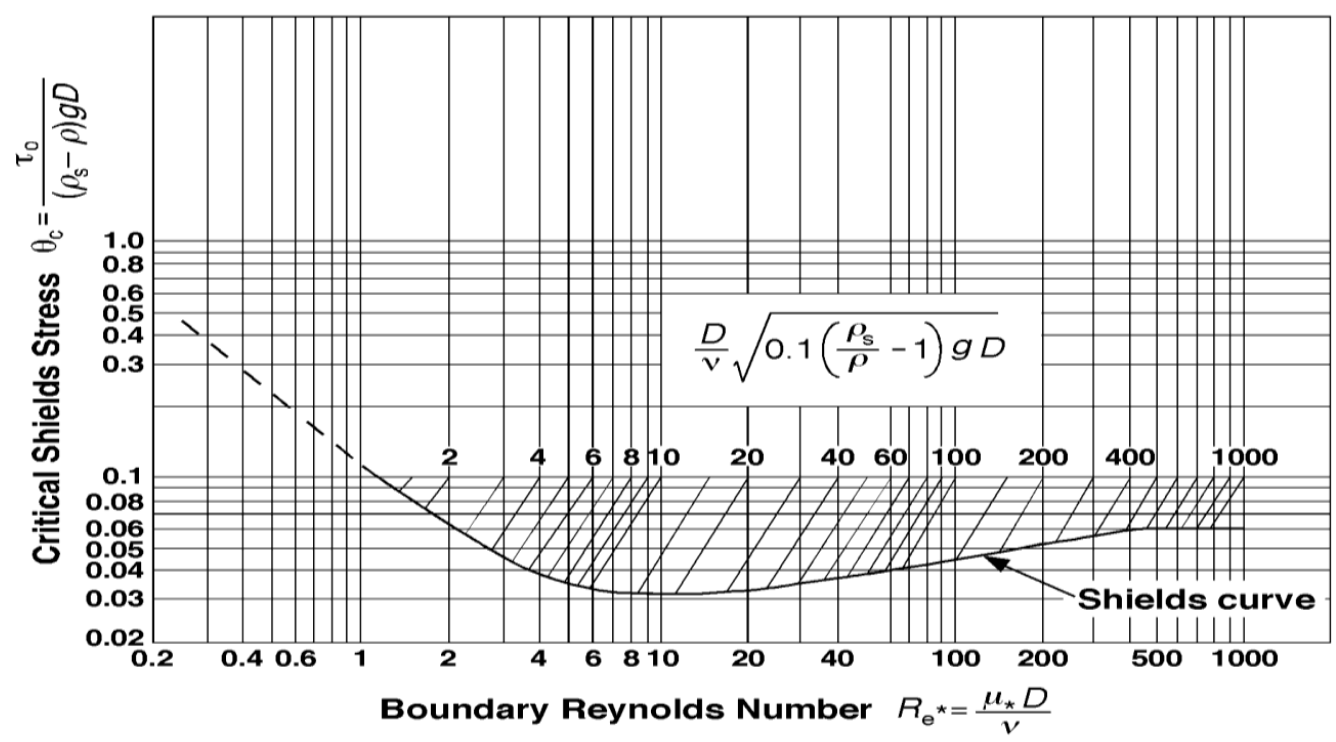

Figure1. Shield diagram for determination of critical motion study (Simon et al. 1992 Incipient motion study)

\section{METHODOLOGY}

\subsection{Experimental work}

Before experiment was started in tilting flume, the bed shear stress determined by using Shields parameter. The clear water condition should be maintain in tilting flume during experiment, it means the bed material of channel is not scour (i.e. clear water condition) and no ripple or scour should be form inside bed material of tilting flume channel. Details of titling flume and other parameters are given below: wetted perimeter of tilting flume $1 \mathrm{~m}$,

Manning's n 0.012,

flow depth(yo) $0.25 \mathrm{~m}$.

tilting flume bed material mean particle size (d50) 0.828 $\mathrm{mm}$

specific gravity 2.60 .

Assume kinematic viscosity $v=9.793 \times 10-7 \mathrm{~m} 2 / \mathrm{s}$.

\section{RESULTS AND DISCUSSION}

tilting flume width $0.5 \mathrm{~m}$,

cross sectional area of tilting flume 0.125 sq.m,

3.1 Calculation of bed shear stress is given by following steps:

Table 1. Calculation for undistorted model(tiling flume)

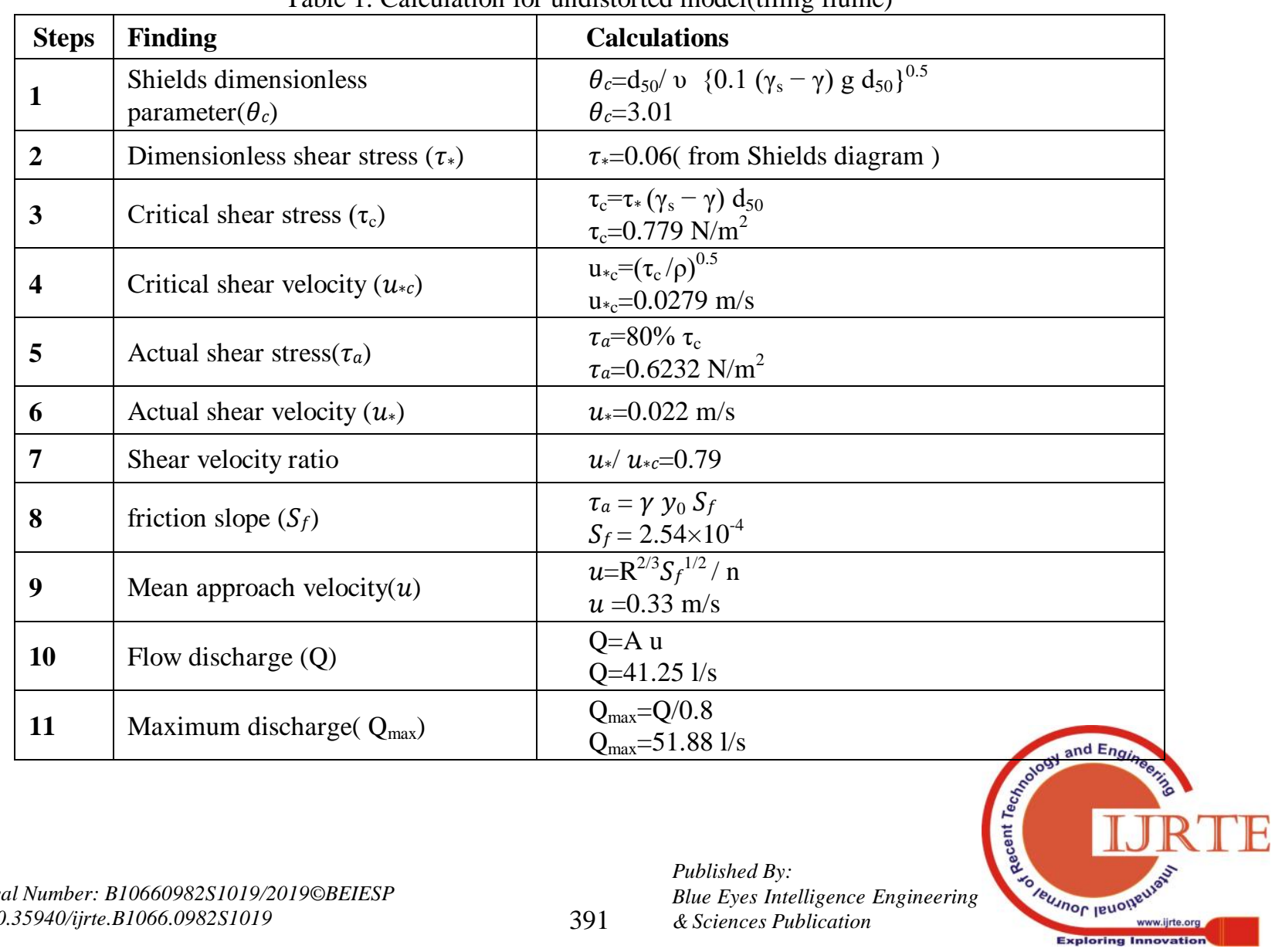




\subsection{Scale physical hydraulic modeling and general hydraulic similitude}

Scaling of hydraulic structures means establishing the relationship between prototype and model in all the manner i.e. dynamic, kinematic and geometric similarity. As we know dynamic similarity is related with forces(pressure, gravity, viscosity, moment, etc), kinematic similarity related with motion(acceleration and velocity) and geometric similarity is related with geometric scale ratio(height, width, length, area etc). All these three similarities between model and prototype should be correlate for hydraulic similitude and modeling.

\subsection{Simulation of bed material from model to prototype}

$\mathrm{d} 50($ model $)=0.828 \mathrm{~mm}$, Manning's $\mathrm{n}($ model $)=$ 0.012 and Consider Input Scale $=50$

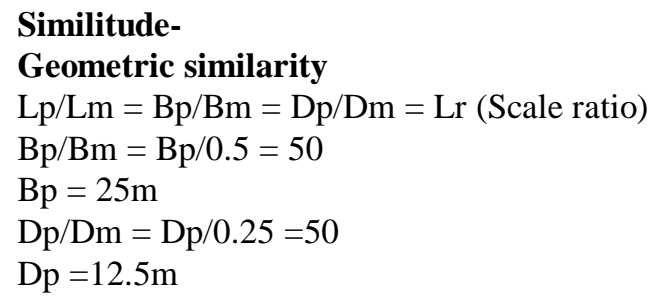

\section{Undistorted scale model (Henderson 1966)}

Manning's n(model) = Manning's n(proto) / (Input Scale) ${ }^{0.16}$

Manning's n(proto) $\quad=0.0224$

Velocity $($ model $)=$ Velocity $($ proto $) /($ Input Scale $) 0.5$

Velocity(proto) $=2.33 \mathrm{~m} / \mathrm{s}$

According to Shield's consideration at the condition of incipient motion,

we have, Model -

Tractive force $\tau \mathrm{m}=\gamma \mathrm{R} S f$

$$
=0.311 \mathrm{~N} / \mathrm{m} 2
$$

According to Shield's consideration at the condition of incipient motion,

$$
=\tau \mathrm{cm} /(\gamma \mathrm{S}-\gamma \mathrm{w}) \mathrm{d} 50=0.06
$$

Critical Tractive Force in Model $\tau \mathrm{cm}=0.779 \mathrm{~N} / \mathrm{m} 2$ Ratio $\tau \mathrm{m} / \tau \mathrm{cm}=0.311 / 0.779=0.399$

Prototype -

Tractive Force $\tau \mathrm{p}=\gamma \mathrm{R} S f$

$$
\begin{aligned}
&= 15.57 \mathrm{~N} / \mathrm{m} 2 \\
& \text { Ratio } \tau \mathrm{p} / \tau \mathrm{cp}= 0.399 \\
& \tau \mathrm{cp}=39.022 \mathrm{~N} / \mathrm{m} 2
\end{aligned}
$$

According to Shield's consideration at the condition of incipient motion,

$$
=\tau \mathrm{cp} /(\gamma \mathrm{S}-\gamma \mathrm{w}) \mathrm{d} 50=0.06
$$

\section{CONCLUSION}

The scaling relationship of particle size is derived from this simulation. The sediment used in undistorted model(tiling flume) is sieved river sand, the mechanical sieve shaker was used to determine the average sediment particle diameter, $50 \%$ of the sediment particles are finer by its weight $(\mathrm{d} 50=0.828 \mathrm{~mm})$ and the corresponding diameter of sediment in prototype is determine by using Shield's parameter which predict sediment size $(\mathrm{d} 50=41.43 \mathrm{~mm})$.

\section{ACKNOWLEDGMENT}

This paper work is carried out under the guidance of my project guide Assistant Professor Piyusha S. Hirpurkar, who has been always helpful and supportive through my entire M-Tech project work.

\section{REFERENCES}

1. D.H.Swart, Hydraulic methods and modeling. "Hydraulic structures, equipment and water data acquisition systems", Vol. I,(1996), pp $1-8,1996$.

2. Dattatray Kisan Rajmane, "Simulation from Proto to Model", IJLTEMAS, Volume IV, Issue VIII, (2015), pp. 90-94.

3. George A. Griffiths, "Downstream hydraulic geometry and hydraulic similitude", water resources research, Vol. 39, NO. 4, (2003), pp.1-6.

4. Gokcen Bombar and Mehmet ukru Guney, "Experimental investigation of sediment transport in steady flows", Academic Journals Scientific, Research and Essays Vol. 5(6), (2010), pp. 582-591.

5. R. J. Garde and K. G. Ranga Raju, "Mechanics of sediment transportation and alluvial stream problems", revised third edition, new age internationa (p) limited publishers, 2000(57-86)

6. R. J. Keller, "Experimental methods and physical modeling. Hydraulic structures", equipment and water data acquisition systems, Vol. I, (1981), pp. 224-244.

7. Valentin Heller, "Scale effects in physical hydraulic engineering models", Journal of Hydraulic Research. Vol. 49, No. 3, (2011), pp. 293-306 